\section{BIOMORPHIC ARCHITECTURE APPROACH IN BUILDING FORM BASED ON ENVIRONMENTAL CONCERN}

\author{
Aulia Fikriarini M. ${ }^{*}$, M. Ishomuddin
}

Architecture Department, Science and Technology Faculty, Maulana Malik Ibrahim Islamic State University of Malang, Indonesia
Article history

Received

7 July 2015

Received in revised form

3 November 2015

Accepted

3 March 2016

\section{Graphical abstract}

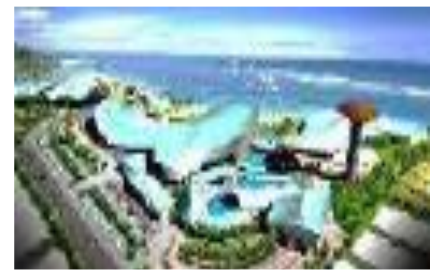

\begin{abstract}
Nature is an excellent learning resource for humans, especially for nature as a source of inspiration in the architectural design. Biomorphic is one of the themes in the architectural approach that has a principle concern for the environment (nature), in which this approach was born from the idea of the importance of nature and oriented to the environment, including climate. The shape, material, structure and mechanisms in the universe, can be used as the basic idea formed in the design of architecture through a process of collaboration between humans and nature itself. The method used in this study is a qualitative design method, through analysis approach biomorphic design theme Architecture. Sea World is the main object in the design, which is a vehicle for recreational and educative to showcase marine life and its beauty in a large aquarium. Sea World that use biomorphic theme, designed by using the analogy of a stingray wing motion transformation into shape, hoping to bring the dynamic character of Sea World and attract visitors as well as having the characteristics of the natural inspiration.
\end{abstract}

Keywords: Biomorphic architecture, Sea World planning

(C) 2016 Penerbit UTM Press. All rights reserved

\subsection{INTRODUCTION}

Allah brings down the source of knowledge on any of His creatures with signs that can be seen and understood by people who think. Nature is one proof of the grace of Allah. People who looked around will see that Allah has given natural wonders countless. Wherever any living being, from plants to animals, on land and at sea, is equipped with amazing privilege.

Biomorphic Architecture is one of the themes back on the idea of natural disposition which is an inexhaustible source of inspiration used as a medium of learning for humans. Everything including the basic idea of design inspiration, can be triggered from living beings created by Allah swt. The theme is applied to the design of Sea World in District Paciran, Lamongan, Indonesia.

\subsection{LITERATURE REVIEW}

Visually, the design of Sea World Lamongan is closely related to the ocean which is a very broad landscape and rich in beauty in it, so we get a lot of benefit from every element that is in the sea. Biomorphic itself comes from two words, namely 'Bios' and 'morphic' which come from the Greek meaning 'human life', and 'shape'. However, in the scientific world, the notion was expanded to 'organic Life' [2], so it is a biomorphic shape or decorative objects are based on or resemble a living organism. Architecture biomorphic design has three principles, namely the principle of the use of materials and structures, forms and principles of sustainability. Architecture presented visually biomorphic shapes are not straight, radical and special, but still on the composition and the harmonization of the tread. The 
principles of nature manifested in a building that is unnatural and abstract [3].

Biomorphic Architecture has visually characteristic shape, structure, and systems that resemble the natural living systems, the use of local materials and supporting materials which use light as a form structure to minimize the problems of sustainability in architecture global. Biomorphic issue-based ecology and metaphor, which is both have a common approach to the design process forms the basis of analysis of other associated forms [3].

\subsection{Form}

The resulting shape in the design of Sea World with this theme, is a shape that resembles a life that exist in nature, may be obtained by analogy or metaphor in natural forms either the original form or forms taken from a transformation / movement of a system of natural life, The development of digital technology is able to assist architects in creating complex shapes, because nature is not only exemplary only of form, but how the natural principle of the work, the principles of nature can be learned and applied in architectural design [3].

\subsection{Materials and Structures}

The shape and style of architecture is always closely related to the construction and material systems that apply to a specific period. Scientific development and education technique gives engineers a great opportunity in which the structure is hardly limited again in a wide span, in a variety of different structures in a variety of new and building materials [3].

The use of materials and structures in this theme is also related to the basic idea of natural life. As well as the power system structure found in nature, incorporated into the design by following the design of the pattern, so that the power system has the same structure.

Biomorphic architecture can be applied through innovative structures and materials. The structure can be made more aesthetically pleasing by using natural formations. The use of structures with organic shapes can be applied to the exterior and the interior of the building. The system can imitate the structure and shape of the structures that exist in nature, because the natural structure has proven its strength. In terms of use of building materials, architectural biomorphic have a tendency in the use of local materials, or made from lightweight materials such as membrane, and other materials that support forms curvilinear [3].

\subsection{Principles of Sustainability}

Architecture biomorphic is an architecture that takes into account ecological, as well as "green architecture" themed nature. The linkage between the form of organic and sustainable architecture exists, but it is not a reciprocal relationship. Both of these architectures have in common in the system sustainability, namely because nature has a system to survive. Architecture biomorphic can bring the benefits of energy efficiency, which is the concept of responsible towards the environment. Being shown will benefit the building itself and the environment for the foreseeable future. Biomorphic architecture should be designed with ecological awareness to create environmentally friendly architecture, so not only presented in terms of shape, but also presented the sustainability of such nature [3].

\subsection{METHODOLOGY}

Searching and data processing can be classified into two categories, namely primary data and secondary data. Primary data is data obtained directly from the source observed and recorded. While secondary data is the data obtained from the data library. The method used in the design analysis techniques, to obtain design concept Sea World, with a grounding thinking of architecture principles biomorphic

\subsection{Primary Data}

Primary data were obtained from observations, interviews and documentation, as described below:

\subsubsection{Observations}

Primary data is the result of direct observations relating to the object that is Sea World. This needs to be done so that the designer can know directly the space requirements in the design, observe and find problems in both the architectural and nonarchitectural sphere, in order to obtain an answer in the form of architectural design.

\subsubsection{Interview (Discussion)}

To obtain objective data, it would require consideration of the opinion and data, as well as information obtained through interviews and discussions to those relating to the design.

\subsubsection{Documentation}

Data were obtained by taking photographs as a form of documentation to show and see the existing condition that will affect the future design concepts and objects

\subsection{Secondary Data}

Secondary data were obtained from the literature in the form of literature, the journal of research and comparative studies. 


\subsubsection{Literature Review}

Library Studies conducted to collect data by studying the literature in the form of case studies relevant to Sea World Lamongan, and at the same time biomorphic Architecture theme, so it will get the recommendations and reference for designing.

\subsubsection{Internet and Books}

The data obtained from the literature about the theoretical basis related to Sea World, the applicable standard of the room and the characteristics of marine animals along with other marine life that should be known.

\subsubsection{Comparison Study (Study)}

The comparative study conducted to obtain information about an object similar to Sea World and the information relating to the object of design that uses biomorphic Architecture theme, so the designers get an overview an object to support the the design

\subsubsection{Design Analysis}

The analysis process performed by the designer as a first step in designing the following stages of analysis functions, space needs analysis based on user activity, the analysis of the shape and structure analysis, which is then applied to the site. The analysis process is interconnected with other aspects of the analysis, which will give a discourse to the designer level according to the design of the site primarily on the surrounding environment.

\subsubsection{Synthesis or Concept Design}

The concept of the design is the basic concept, site, space, shape and the concept of the structure of the basic guidelines in the design, resulting from the study of previous analysis. This design concept, is the most appropriate the design response to the site conditions, objects, and Sea World as well as the the design theme issue.

\subsection{RESULTS AND DISCUSSION}

Results of design is an elaboration of the concept of "Transformation wing movement" of fish Pari, using biomorphic architecture principles, that can support activities and educational tour at sea world in the area of marine tourism in Lamongan

\subsection{Results Tread Design}

\subsubsection{Patterns of Buildings}

Patterns on the design of mass Sea World resembles a linear curve " $\mathrm{S}$ ", as a form of application biomorphic dynamic theme to the concept of wing movement stingray wavy curved "S". Patterns order mass is divided into three zones based on activity, namely; Public, Private and Semi Private. Border zone is characterized by differences in the flooring material used, so it will be easier for users to perform their activities. Private zone in the limit by providing a pool that surrounds the area, so it is not accessible to all visitors without tickets. Limits are designed to give the impression open but cannot be achieved easily. Building curved "S" become a point of interest layout plan and become circulation director aspects by following the movement of the linear pattern. While other buildings as a support, placed at a certain point in consideration aspects of service activities can be affordable. Basically site have a zone of land and sea zones, but to anticipate the negative sea air and seawater, then the placement of the building mass is placed in the zone of the land. In addition, the building located on the land area is expected to have ease of accessibility, while the area of beach / ocean used as an open area, so visitors can enjoy the atmosphere of the beach / ocean pristine which means the design principles do not damage the marine environment. Figure 1 shows the patterns on the design of mass Sea World resembles a linear curve "S", as a form of application

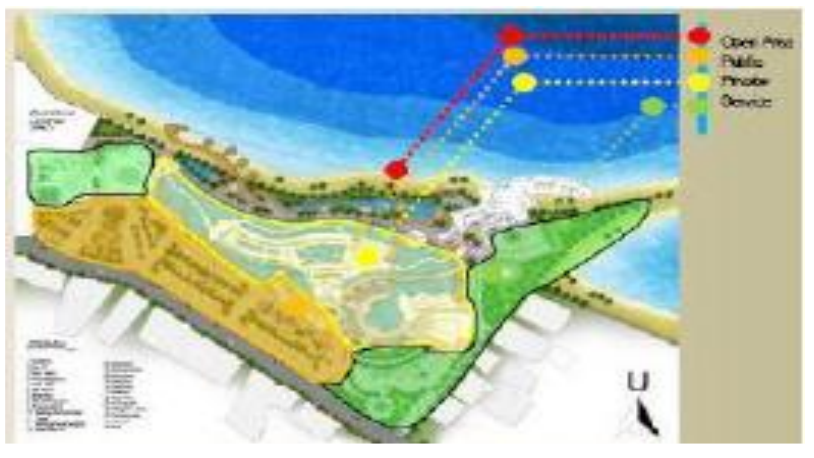

Figure 1 Patterns on the design of mass Sea World resembles a linear curve "S", as a form of application

\subsubsection{Accessibility and Circulation}

Accessibility in site is divided into three accesses: access to vehicles, visitors, vehicles employee / service and pedestrian access from Marine Tourism Lamongan (WBL) itself. Accessibility to the vehicle in the limit on public zones, so that visitors are directed to walk to enter the arena of tourism. This condition is affected by the shape of site that extends and contoured, so that this condition can be used as a solution to accessibility. Tread can only be achieved from south direction immediately adjacent to the road. Laying the plaza in front of the area will give the impression of an open at the site, so that people will be more interested. Figure 2 shows the access and circulation by function and achievement. 


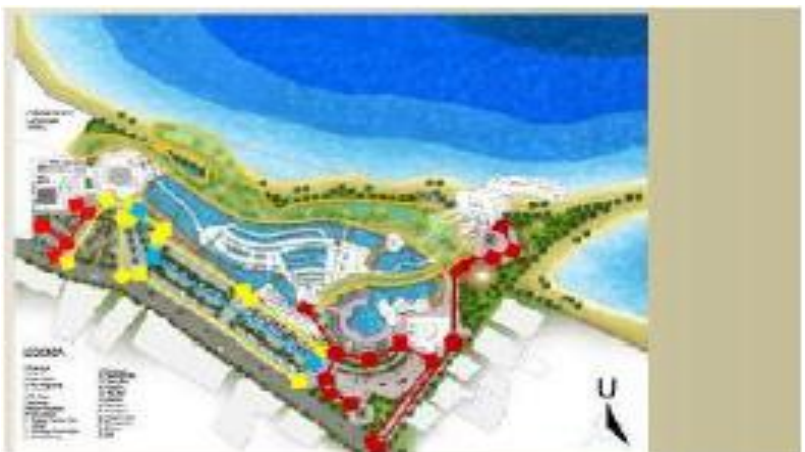

Figure 2 Access and circulation by function and achievement

\subsubsection{Utilization Potential of Tread}

\section{a. Vegetation}

The vegetation used in site does not change in accordance with the concept. Some types of vegetation used on site is as follows:

1. Vegetation shade placed in areas where people gather and along the circulation area of the sea to provide user convenience in attainment. The vegetation used is neem tree, as a form of preservation of existing vegetation on the site. Vegetation is placed in the plaza area, parking, and the pier.

2. The vegetation trimmer placed in the circulation area, namely sansivera, agave, iris. This vegetation serves as a director at a time deduction heat on site, so that visitors will feel comfortable

3. The steering vegetation placed on the circulation of two and four-wheeled vehicles that make it easier for users to access with vehicles. The vegetation used are coconut and palm trees.

4. Vegetation "mangrove" is placed between the areas of land and sea areas. This vegetation can create a more stable soil condition, stronger than the threat of abrasion, while preserving the existing plant at the site.

Site conditions that are in the coastal area of air causes the acid will damage building materials, the placement of vegetation as a barrier or filter air before entering the site and building, be an alternative to placement evenly on the beach. Figure 3 shows the vegetation is used as an air filter (acid) from the sea breeze

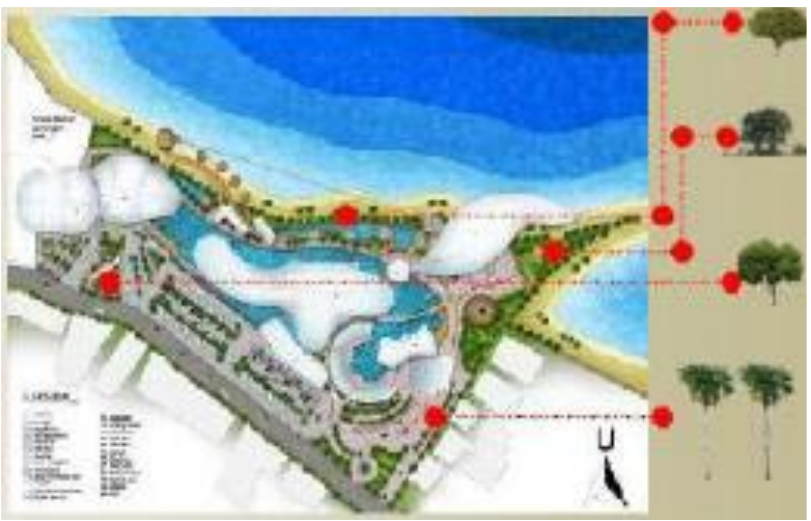

Figure 3 Vegetation is used as an air filter (acid) from the sea breeze

\section{b. Wind}

The wind speed fairly high in the sea area can be used as a potential in the design. The condition used as a natural air in buildings. In addition, the shape of the roof on the building Sea World This follows the pattern of the wind in site, so the wind can both directed distribution to the rest of site, nor with the placement of vegetation as wind steering. Figure 4 shows the building form serves to drive circulation of winds coming from the wing movement "Ikan Pari".

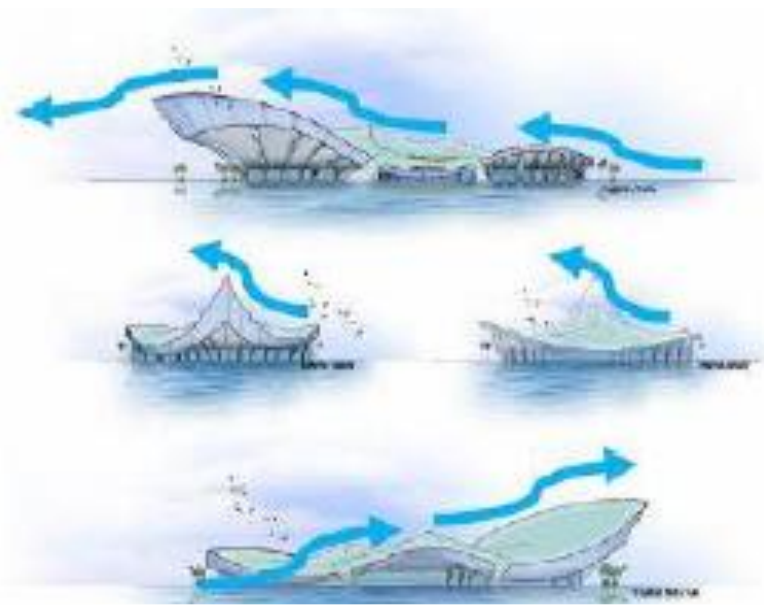

Figure 4 Building form serves to drive circulation of winds coming from the wing movement "Ikan Pari"

\subsubsection{View}

Views of the expanse of the sea at the site are the potential for the site that has a strong influence to the design. Scenic expanse of the sea will give a different feel and the main attraction for tourist visitors. Glass is a material chosen on the facade wall mounted surrounds each side of the building, with the intention of giving freedom to the visitor to choose the desired view. Overall, the shape of the building surrounded by a sea water pool illustrates the "stingray" are being floated, because the glass 
material will give the impression boundless (transparent), so visitors see the building as hovering over the pool to the sea. Figure 5 shows the building and building arrangements oriented to sea and Figure 6 shows the glass material is installed to maximize the views from inside the building to the outside space

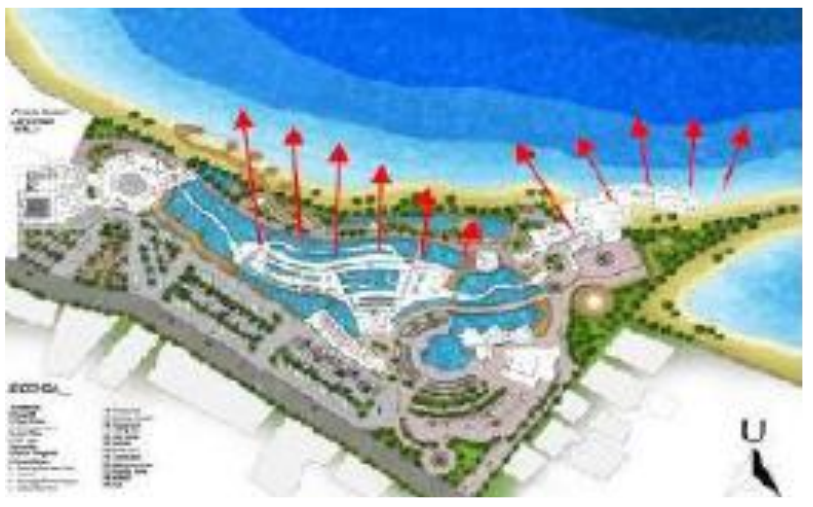

Figure 5 building and building arrangements oriented to sea

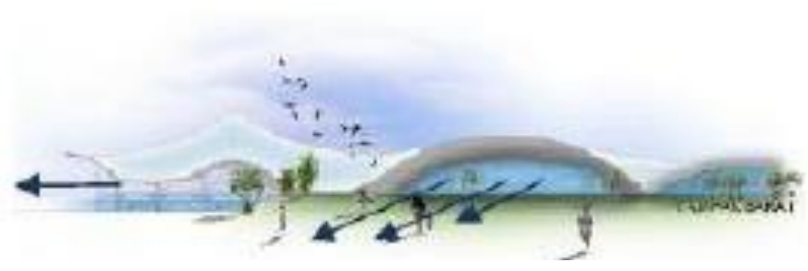

Figure 6 The glass material is installed to maximize the views from inside the building to the outside space

\subsubsection{Lighting and Air}

Sea World in Lamongan marine tourism area has natural light sources. Natural light obtained through the wide-open window to the second floor with a full glass materials, ventilation and void. However, to avoid the excessive heat of the sun, then this building has a roof formation width as shading, from the formation wing Pari fish, so that light entering to building is simply the refraction of light, while the heat is reduced. In addition, to reduce solar radiation, the building was designed layering using window film material so that radiation can be retained but the required light can get into the building. In addition to the above, the lighting in buildings can be done several ways, as follows:

1. Transparently designed building on the east side with the formation of a wide-open roof, the direction comes from the sun in the morning. While the west side using the shape of the roof covering the interior, so that the light of the sun's heat in the afternoon cannot enter the building.

2. Open the two sides of the building, which is from the south and the north, so that light can get into the building indirectly.
3. For spaces that do not allow gets sunlight from the side of the wall, then do light presented with top lighting and artificial lighting systems.

4. Another element to support is a pool of light that reflected solar radiation.

Figure 7 shows the open open roof shape oriented in natural light (east) and Figure 8 shows the reflection of light that comes from the pool, can enrich the light inside the room.

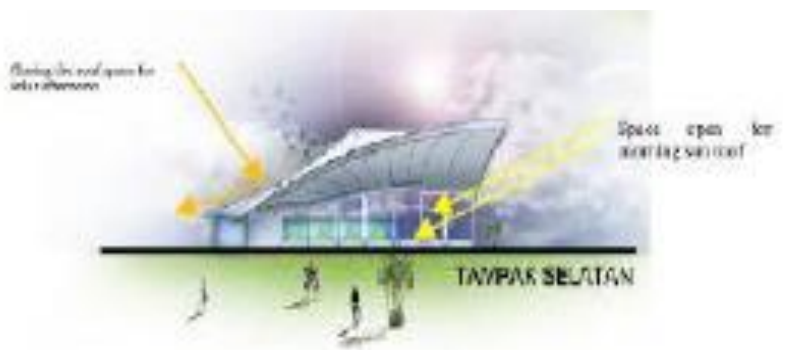

Figure 7 open roof shape oriented in natural light (east)

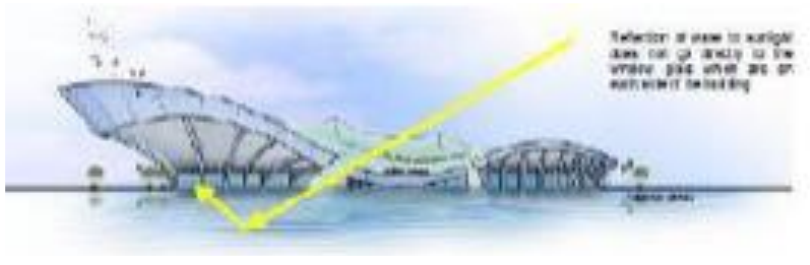

Figure 8 the reflection of light that comes from the pool, can enrich the light inside the room

\subsubsection{Temperature}

Air circulation in the building was designed to use natural air circulation elements, like windows, vents, and void. This condition is reinforced by the existence of a pool that is capable of cooling the air in the room. For special enclosed space such as auditorium, using artificial air circulation (air conditioner) as well as on the first floor which is located in the basement and surrounded by fish ponds. Figure 9 shows the arrangement of the building at the site, following the pattern of wind movement. Figure 10 shows the air circulation in the building was designed to use natural air circulation elements

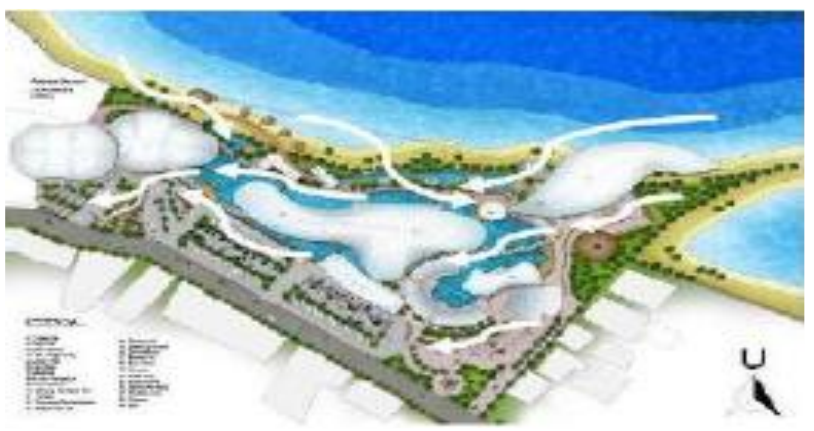

Figure 9 Arrangement of the building at the site, following the pattern of wind movement 

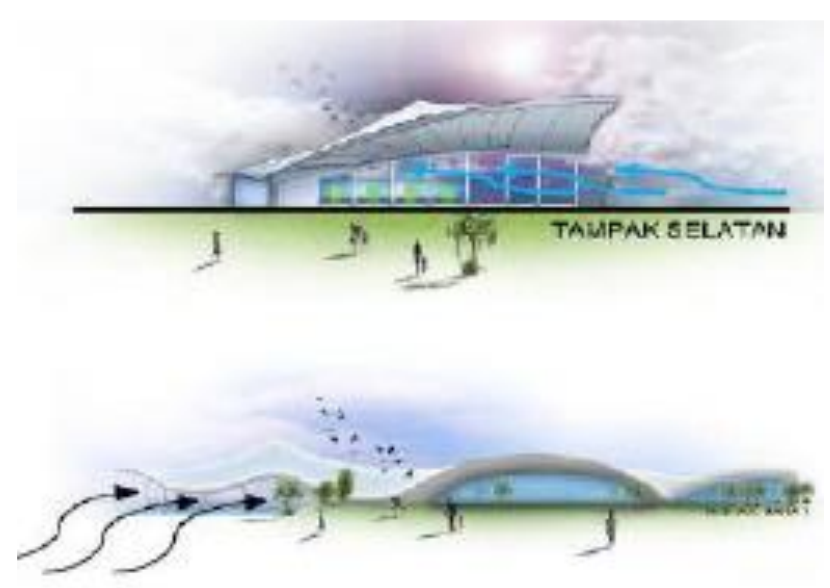

Figure 10 Air circulation in the building was designed to use natural air circulation elements

\subsection{CONCLUSION}

Sea World Region Marine Tourism Lamongan is a center for tourist rides depicting sea world with educational tours in it. The purpose of the planning Sea World this, is to increase the return number of tourist visitors and seeks to present the beauty of the sea world creatures of Allah, is expected to raise the potential of Indonesia's marine resources to be better, and to benefit society as a place / vehicle for recreational and educational. Sea World which is a vehicle for recreation must have a unique shape with the aim of attracting more visitor arrivals, so the theme of biomorphic Architecture was selected as one the idea of a theme that can support the presence of a unique shape, structure and values of sustainability, which is based on natural resources as a place of inspiration inexhaustible, and can be used as learning material for humans. All the inspiration in this design, born of living creatures created by Allah swt.

\section{References}

[1] Habibi, A. D. 2012. Coral Reef Aquaculture Centers in Lamongan District. Research Method at the Department of Architecture UIN Maliki, Malang. Unpublished.

[2] Poespita. 1998. Bachelor Thesis at Petra Christian University, Jakarta. Unpublished.

[3] Rasikha, T. N. 2009. Contemporary Organic Architecture. Bachelor Thesis at the Faculty of Engineering Department of Architecture at the University of Indonesia, Jakarta. Unpublished.

[4] Ubay, Muchammad. 2013. Sports Aeromodelling Centre in Malang. Pre Final Project Report of the Department of Architecture UIN Maliki. Unfortunate; Unpublished. 